\title{
Short Communication: Optimization of extraction of sulfhydryl compounds from several legumes seeds in Indonesia with various ethanol concentrations
}

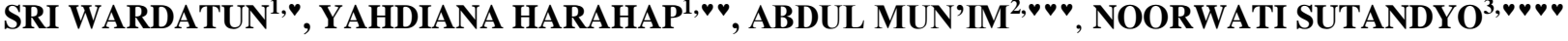 \\ ${ }^{1}$ Laboratory of Bioavailability and Bioequivalence, Faculty of Pharmacy, Universitas Indonesia. Kampus UI, Depok 16242, West Java, Indonesia. \\ Tel.: +62-21-7270031, Fax.: +62-21-7863433, •email: sri.wardatun07@gmail.com, •vemail: yahdiana03@yahoo.com \\ ${ }^{2}$ Laboratory of Phytochemistry, Faculty of Pharmacy, Universitas Indonesia. Kampus UI, Depok, 16424, West Java, Indonesia. Tel. +62-21-7270031, \\ Fax.: +62-21-7863433, ••email: abdul.munim61@ui.ac.id \\ ${ }^{3}$ Dharmais Cancer Hospital. Jl. Letjen S. Parman No. 84-86, Palmerah, Jakarta Pusat 11420, Jakarta, Indonesia. Tel./fax.: +62-21-5681570, \\ vvvemail: noorwatis3@yahoo.com
}

Manuscript received: 16 October 2019. Revision accepted: 15 February 2020

\begin{abstract}
Wardatun S, Harahap Y, Mun'im A. 2020. Short Communication: Optimization of extraction of sulfhydryl compounds from several legumes seeds in Indonesia with various ethanol concentrations. Biodiversitas 21: 1060-1064. Leucaena leucocephala (Lam.) de Wit (petai Cina), Parkia speciosa Hassk. (petai), and Archidendron jiringa (Jack) I.C. Nielsen (jengkol) seeds extracts contain sulfhydryl compounds and have various therapeutic properties. The main objective of this research was to compare the effect of various ethanol concentration on the yield of extract and levels of sulfhydryl compounds from leguminous seeds. Dried seeds were macerated at room temperature $\left(25^{\circ} \mathrm{C}\right)$ with a ratio of solids and solvents was $1: 10$. The solvent concentrations used were $30 \%, 50 \%, 70 \%$ and $96 \%$ ethanol. The yield of extract was expressed as the ratio of the weight of extract to the weight of dried seeds, the level of sulfhydryl compound was expressed as reduced L-glutathione (GSH) equivalent. The level of sulfhydryl compounds was determined by Ellman reagent and further analyzed using a spectrophotometer at $411 \mathrm{~nm}$ wavelength. Stink bean produced the highest yield of extract, while the highest level of sulfhydryl compounds was obtained from petai cina seed extract. The concentration of ethanol gave a significant difference to the yield of extract and the level of sulfhydryl compounds. The results showed that ethanol concentration affected the efficiency of the extraction of total sulfhydryl compounds and the yield of the extract on leguminous seeds.
\end{abstract}

Keywords: Leguminous seed, solvent, sulfhydryl compound, yield of extract

\section{INTRODUCTION}

Leucaena leucocephala (Lam.) de Wit is a tropical leguminous tree in the family of Leguminosae found in Indonesia and the other tropical areas (Syamsudin et al. 2010; Verma 2016). The common name of L. leucocephala is petai cina or lamtoro (Indonesia) and white lead tree (English) (Soetjipto et al. 2019). Parkia speciosa Hassk. or stink bean in Indonesia and Malaysia is known as petai (Tocmo et al. 2016; Chhikara et al. 2018). Archidendron jiringa (Jack) I.C. Nielsen is locally as known as jering" as well as jengkol in Indonesia. P. speciosa and A. jiringa were the other tropical leguminous tree in the family of Leguminosae. Seeds from these legumes often used as food sources and have several health benefits. L. leucocephala used as anthelmintic, antidiabetic (Abdelhady and Abdallah 2016; She et al. 2017 ), anticancer and anti-metastasis (She et al. 2017), antioxidant and tyrosinase inhibitor (Li 2012). $P$. speciosa seeds have antioxidant, antiproliferative and hypoglycemic activity (Chhikara et al. 2018). A. jiringa seeds used as antiulcerogenic and have pancreatic lipase inhibitory activity (Abdel et al. 2012; Seyedan et al. 2015). Seeds of these plants have distinctive aroma suggesting the presence of sulfur/thiol compounds (Suvachittanont et al 1996). The sulfur compound in seed could be cysteine, and their derivatives such as glutathione, djenkolic acid and thiazolidine-4-carboxylic acid (TCA) which is often called thioproline (Suvachittanont et al. 1996). Thiol compound has functional groups of sulfur and hydrogen atoms (-SH) often called sulfhydryl compounds (Baron and Sochor 2013). Sulfhydryl compounds in the body play the role of glutathione ( $\Upsilon$-glutamyl-cysteinyl-glycine; GSH) and have the function of antioxidants to scavenge reactive oxygen and nitrogen as well as a cofactor in several types of enzymes (Gaucher et al. 2018; Lushchak 2012).

Extraction is the separation of the soluble plant metabolites leaving insoluble residues (Azwanida 2015). The extraction process is an important part of taking active compounds (Gupta et al. 2012; Azmir et al. 2013). The extraction of sulfhydryl compounds from leguminous seeds can be done optimally if the solvents used are suitable. The choice of solvent will determine the type of compound being extracted from the sample (Azwanida 2015). A number of leguminous seeds contain water-soluble sulfhydryl compounds. The extraction of sulfhydryl compounds from Leguminous seeds has been done by using water as a solvent (Suvachittanont et al. 1996). The use of water as a solvent has no impact on the environment but it dissolves undesired protein and polysaccharides (Shi et al. 2003; Plaza and Turner 2015). The presence of 
protein and polysaccharides results in concentration polarization and reduced filterability when the filter membrane used for purification (Shi et al. 2003). Using water as a solvent in extraction might be energy demanding in cases where water needs to be removed by evaporation (Plaza and Turner 2015). Ethanol is an organic and nontoxic solvent, and most widely used for extraction (Alam and Bristi 2013). High concentrations of ethanol increase the cost of extraction (Shi et al. 2003). Solvent concentration plays an important role in the efficiency and affects the quantity and secondary metabolites composition (Pandey and Tripathi 2014; Sun et al. 2015). The objective of this study was to optimize the extraction conditions by varying ethanol concentration to maximize the yield of extract and levels of sulfhydryl containing-compounds from leguminous seeds.

\section{MATERIALS AND METHODS}

\section{Chemicals and samples}

Reduced L-Glutathione as standard and 5-5 dithiobis-2nitrobenzoic acid (DTNB; Ellman's reagent) from Sigma Aldrich, ethanol from Merck, potassium phosphate monobasic, sodium hydroxide (Merck). All chemicals used were analytical grade purchased from Merck.

Fresh seeds of $P$. speciosa and A. jiringa were purchased from the local market in Bogor, Indonesia. The seeds were sliced (3-4 mm) and dried in an oven at $40^{\circ} \mathrm{C}$ for 86 hours. L. leucocephala seeds were collected from Ciomas, Bogor-Indonesia in December 2018 then dried in an oven at $40^{\circ} \mathrm{C}$ for 86 hours. The samples were characterized at The Center for Plant Conservation, Botanic Gardens, Indonesia. All samples were mature seeds. The weight of dried seeds was determined after air drying and weighed until a constant weight was obtained. Dried weights of these seeds were found to be 38.56; 27.58 and $29.71 \%$ of fresh weight for $L$. leucocephala, P. speciosa and $A$. jiringa, respectively

\section{Preparation of extract}

Dried seeds were crushed to powders. The powder of seeds (50 grams) was macerated with $250 \mathrm{~mL}$ different concentrations of ethanol $(30 \%, 50 \%, 70 \%$, and $96 \%)$ for 24 hours, respectively. Remaceration was done in $2 \times 24$ hours with $150 \mathrm{~mL}$ ethanol and $100 \mathrm{~mL}$ ethanol (Azwanida 2015). The ethanol extract was separated from the residual seed powder. The filtrate was evaporated with a rotary evaporator. Water content in the crude extract was determined gravimetrically. Extraction was done in triplicates.

\section{The yield of extract}

The dried extract was weighed to obtain the yield of extract from the following equation:

The yield of extract $=\mathrm{W}_{\text {extract }} / \mathrm{W}_{\text {dried seeds. We extract }}$ is the weight of the extract $\mathrm{W}_{\text {dried seeds }}$ are the weight of dried seed (Xu et al. 2017).

\section{Analysis of total sulfhydryl compound in extract}

Analysis of total sulfhydryl compound was carried out according to Ellman 1959; Haque et al. 2003; Khan et al. 2012. The extract was weighed and dissolved with distilled water in a conical flask then filtered with a syringe filter. In brief, $2300 \mu \mathrm{L}$ of phosphate buffer $\left(\mathrm{K}_{2} \mathrm{HPO}_{4} / \mathrm{NaOH}, 200\right.$ $\mathrm{mM}, \mathrm{pH}$ 7.6) were mixed with $200 \mu \mathrm{L}$ sample. Then, 500 $\mu \mathrm{L}$ of DTNB (5,5'-dithio-bis (2-nitrobenzoic acid) solution ( $1 \mathrm{mM}$ in the same phosphate buffer) were added and the mixture was shaken using vortex in 10 seconds and kept at room temperature $\left(20^{\circ} \mathrm{C}\right)$ for 2 minutes. The absorbance of the filtrate of the sample was measured at $\lambda_{\max } 411 \mathrm{~nm}$ against a blank containing buffer instead of the DTNB solution using Jasco V-730 UV/VIS double beam spectrophotometer. Total sulfhydryl compound was determined using the standard curve of reduced Lglutathione $(\mathrm{GSH})$ obtained from different concentrations of $\operatorname{GSH}(50,100,150,200,250$, and $300 \mu \mathrm{g} / \mathrm{mL})$. The levels of total sulfhydryl compound expressed as GSH equivalent ( $\mu \mathrm{mol} / 100 \mathrm{~g}$ dry seeds).

\section{Standard curve of reduced glutathione}

Phosphate buffer solution $(2300 \mu \mathrm{L})$ of $\mathrm{pH} 7.6$ was added to $200 \mu \mathrm{L}$ of $50,100,150,200,250$, and $300 \mu \mathrm{g} / \mathrm{mL}$ solutions of GSH, followed by the addition of $500 \mu \mathrm{L}$ of 1 mM DTNB stock solution. The mixture was shaken using vortex in 10 seconds and kept at room temperature $\left(20^{\circ} \mathrm{C}\right)$ for 2 minutes. The absorbance was measured at $\lambda_{\max } 411$ nm. The standard curve was constructed between concentration with absorbance. Straight-line was drawn. The Coefficient regression was 0.9991 .

\section{Statistical analysis}

All experiments were carried out in triplicates. Results were presented as average $\pm \mathrm{SD}$. The significant difference between treatment was analyzed using the ANOVA. $\mathrm{P}<0.05$ was considered as the level of significance.

\section{RESULTS AND DISCUSSION}

\section{The yield of extract}

The yield of extract in different concentrations of the solvent had been varied depending on the concentration of ethanol (Figure 1). The yield of $P$. speciosa extract derived from $30 \%$ ethanol and $96 \%$ ethanol did not show a significant difference, and the yield of extract from $50 \%$ and $70 \%$ ethanol showed no significant difference. The yield of $P$. speciosa seed extract from $30 \%$ ethanol and $96 \%$ ethanol, when compared to the yield of $P$. speciosa, extract from $50 \%$ ethanol and $70 \%$ ethanol showed significant differences.

A solvent of $96 \%$ ethanol results in the lowest yield of extract, while $30 \%$ ethanol results in the highest yield of extract at A. jiringa. Ethanol concentrations of $50 \%$ and $70 \%$ did not show a significant yield of $A$. jiringa extract. The concentration of $30 \%$ ethanol and $96 \%$ ethanol showed a significant effect on the yield of extract. The ethanol concentration of $96 \%$ results in the lowest yield of extract, while $30 \%$ ethanol results in the highest yield of $L$. 
leucocephala extract, while ethanol concentrations of $30 \%$ and $50 \%$ did not show a significant yield of $L$. leucocephala extract. Statistical analysis showed that ethanol concentrations of $96 \%, 70 \%$, and $30 \%$ ethanol showed a significant yield of leguminous seeds extract.

\section{Total sulfhydryl compound}

Figure 2 showed the total sulfhydryl compound of leguminous seeds expressed as GSH equivalent. The results showed that the total sulfhydryl compound extracted from different ethanol concentrations varied. The ethanol concentration of $30 \%$ produced the highest level of total sulfhydryl compound in $P$. speciosa and A. jiringa seeds, and $50 \%$ ethanol produced the highest total sulfhydryl compound in L. leucocephala seeds. The ethanol concentration of $96 \%$ ethanol produced the lowest level of total sulfhydryl compound in these leguminous seeds. $L$. leucocephala seeds produced the highest total sulfhydryl compound compared to other Leguminous seeds. Statistical analysis showed that different ethanol concentrations significantly affected the level of total sulfhydryl compounds $\mathrm{P}<0.05)$.

\section{Discussion}

Sulfhydryl compounds can act in the body as glutathione ( $\Upsilon$-glutamyl-cysteinyl-glycine; GSH). GSH may play a role during oxidative stress and act as an antioxidant (Lushchak 2012). The presence of sulfhydryl compounds can be smelled from its distinctive aroma (Suvachittanont et al. 1996). Solvent has a critical role in the amount of extracted compounds (Pandey and Tripathi 2014). The solvent is mainly selected in terms of availability, cost, inertness, toxicity, environmental fate, solubility, polarity and boiling point. Polarity plays a critical role as the polar solvent is able to extract polar compounds (Maltese et al. 2009). The concentration of solvent could affect viscosity, change the dielectric constant and could produce a difference of polarity solution extract (Shuai and Luterbacher 2016). On the basis of their chemical properties, different compounds are extracted from different polarity solvents (Rauf et al. 2018). Maceration methods are used to avoid the destruction of thermolabile sulfhydryl compounds. The maceration method is the most suitable for extracting the thermolabile compounds (Pandey and Tripathi 2014).

Study on the levels of thiol compound in Leguminous seeds using distilled water as a solvent has been done in Thailand with the following results: L. leucocephala $(1.5$ $\mathrm{mmol} / 100 \mathrm{~g}$ dried seeds), P. speciosa $(4.40 \mathrm{mmol} / 100 \mathrm{~g}$ dried seeds), and A. jiringa (0.30 mmol/ $100 \mathrm{~g}$ dried seeds) (Suvachittanont et al. 1996). Figure 1 showed that different ethanol concentrations produced different amounts of extract. This is in agreement with the result by Shuai and Luterbacher (2016) that varying ethanol concentrations result in the difference in yield of extract (Shuai and Luterbacher 2016). Different ethanol concentrations have different polarities. Water has a higher polarity index than ethanol. Polarity index of water and ethanol was 10.2 and 5.2, respectively (Ramluckan et al. 2014). The addition of ethanol to water caused a decrease in the polarity index of the mixture. The use of mixed solvents allows all compounds to be extracted because of changes in polarity. The use of mixed solvents increases the efficiency of extraction, while the use of a single solvent does not ensure that all of the phytochemical compounds in the plant could be extracted (Rauf et al. 2018). Figure 1 showed that an increase in ethanol concentration causes the yield of the extract to decrease. This can be caused that the compounds in the extract have high polarity, so it was difficult to dissolve in low polarity solvents. $P$. speciosa produced the highest yield of extract in $96 \%$ ethanol concentration. This can be caused that $P$. speciosa contain chemical compounds that are more soluble in $96 \%$ ethanol (Chhikara et al. 2018).

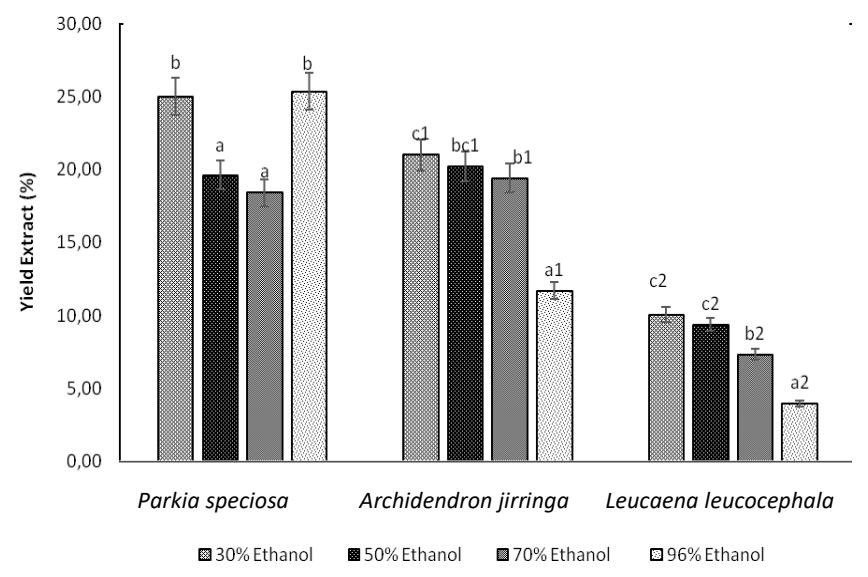

Figure 1. Effect of solvent concentration to yield of leguminous seed extracts

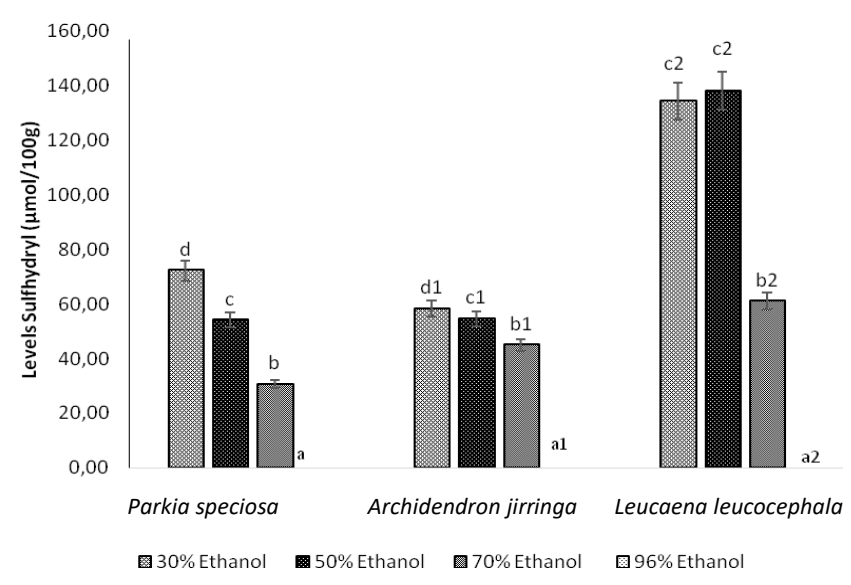

Figure 2. The effect of solvent concentrations on sulfhydryl levels of leguminous seeds 
Sulfhydryl compounds are water-soluble and oil-soluble (de Vallle et al. 2008). Water-soluble sulfhydryl compounds could be extracted with ethanol because ethanol was a polar solvent (Shuai and Luterbacher 2016). Differences in ethanol concentration cause differences in the amount of extracted sulfhydryl. Lower ethanol concentrations produced higher levels of extracted sulfhydryl in all leguminous seeds. The concentration of $30 \%$ ethanol gave the highest levels of sulfhydryl compounds in all leguminous seeds. The polarity index of $30 \%$ ethanol was higher than other ethanol concentrations. Sulfhydryl compounds were polar compounds that were more soluble in 30\% ethanol. The 96\% ethanol concentration unable to extract sulfhydryl compound hence sulfhydryl compound in $96 \%$ ethanol was not detected or below the detection limit. Water-soluble sulfhydryl compounds contain allyl sulfur with carboxylic groups (Tapiero et al. 2004). The ethanol concentration of $96 \%$ has a low polarity index, so the solvent was unable to extract sulfhydryl compounds. P. speciosa contains cyclic and non-cyclic organosulfides which comprise $36 \%$ of the total volatiles. Volatile organosulfides are more soluble in $n$ hexane than ethanol (Tocmo et al. 2016). The results of this study showed that non-volatile organosulfides are more soluble in low concentrations of ethanol. The content of sulfhydryl compounds of L. leucocephala was higher than $P$. speciosa and A. jiringa. Sulfhydryl compounds in seeds could be cysteine and their derivates such as glutathione, djenkolic acid, and thiazolidine-4-carboxylic acid. These compounds are soluble in polar solvents (Suvachittanont et al. 1996).

The level of sulfhydryl compounds in Leguminous seeds in Indonesia differs from the levels of sulfhydryl compound in Leguminous seeds from Thailand (Suvachittanont et al. 1996). The plant growth and various cultivation affect on chemical composition (Martins et al. 2016). The use of ethanol for solvents and the fresh or dried samples in this research can affect to levels of sulfhydryl compounds obtained. The drying process may affect the content of available sulfhydryl compounds (Suvachittanont et al. 1996). The evaporation process of the extract using a rotary evaporator at $40^{\circ} \mathrm{C}$ may also affect the total sulfhydryl content. The level of total sulfhydryl compounds in the seeds of $L$. leucocephala was the highest compared to other Leguminous seeds. However, this finding differed from the result of Suvachittanont et al. (1996), they used water distilled for extraction and this research used ethanol for extracted. The type solvent and solvent concentration affect the quality, quantity, and composition of secondary metabolite extracted (Pandey and Tripathi 2014). The statistical analysis showed that ethanol concentrations affect the yield of extract and the efficiency of extraction of total sulfhydryl-containing compounds in Leguminous seeds. The best ethanol concentration for extracting sulfhydryl compounds in legumes seeds was $30 \%$ ethanol solvent.

\section{ACKNOWLEDGEMENTS}

This research was funded by Universitas Indonesia for a dissertation grant NKB-0094/UN2.R3.1/HKP.05.00/2019.

\section{REFERENCES}

Abdel I, Ibrahim A, Qader SW, Abdulla MA, Nimir AR, Abdelwahab SI, Al-bayaty FH. 2012. Effects of Pithecellobium jiringa ethanol extract against ethanol-induced gastric mucosal injuries in Sprague-Dawley Rats. Molecules 1: 2796-2811.

Abdelhady N, Abdallah G. 2016. HPLC/MS/MS study of phenolic compounds of Leucaena leucocephala legumes monitored with their in vitro antihyperglycemic activity. Eur J Med Plants 17 (4): 1-9.

Alam N, Bristi NJ. 2013. Review on in vivo and in vitro methods evaluation of the antioxidant activity. Saudi Pharm J 21: 143-152.

Azwanida NN. 2015. A review on the extraction methods use in medicinal plants, principle, strength and limitation. Med Aromat Plants 04 (03): 3-8.

Azmir J, Zaidul ISM, Rahman MM, Sharif KM, Mohamed A, Sahena F, Jahurul MHA, Ghafoor A, Norulaini NAN, Omar AKM. 2013. Techniques for extraction of bioactive compounds from plant materials: a review. J Food Eng 117 (4): 426-436.

Baron M, Sochor J. 2013. Estimation of thiol compounds cysteine and homocysteine in sources of protein by means of electrochemical techniques. Int J Electrochem Sci 8: 11072-11086.

Chhikara N, Devi HR, Jaglan S, Sharma P, and Gupta P. 2018. Bioactive compounds, food applications and health benefits of Parkia speciosa (stinky beans): a review. Agric Food Secur (46): 1-9.

del Valle JM, Mena C, Budinich M. 2008. Extraction of garlic with supercritical $\mathrm{CO}_{2}$ and conventional organic solvents. Braz J Chem Eng 25 (3): 535-542.

Ellman GL. 1959. Tissue sulfhydryl groups. Arch Biochem Biophys 82: 70-77.

Gaucher C, Boudier A, Bonetti J, Clarot I, Leroy P, Parent M. 2018. Glutathione: antioxidant properties dedicated to nanotechnologies. Antioxidant 7 (62): 1-21.

Gupta A, Naraniwal M, Kothari V. 2012. Modern extraction methods for preparation of bioactive plant extracts. Int J Appl Nat Sci (IJANS) 1 (1): 8-26.

Haque R, Parvez S, Pandey S, Sayeed I, Ali M, Raisuddin S. 2003. Aqueous extract of walnut (Juglans regia L.) protects mice against cyclophosphamide-inducedd biochemical toxicity. Human Exp Toxicol 22: 473-480.

Khan H, Khan F, Khan BA, Wahab A, Jan SU, Mukhtair M, Ullah N, Haque N, Farid A. 2012. Oxidation of glutathione ( GSH ) in blood plasma due to oxidative stressors : a case study of silver. Afr J Pharm Pharmacol 6 (21): 1502-1507.

Li HT. 2012. Antioxidant and tyrosinase inhibitor from Leucaena leucocephala. Afr J Biotechnol 11 (77): 14182-14185.

Lushchak VI. 2012. Glutathione homeostasis and functions: potential targets for medical interventions. J Amino Acids 2012: 1-26.

Maltese F, Kooy F, Van Der, Verpoorte R. 2009. Solvent derived artifacts in natural products chemistry. Nat Prod Commun 4 (3), 447-454.

Martins N, Petropolous S, Ferreira ICFR. 2016. Chemical composition and bioactive compounds of garlic (Allium sativum $\mathrm{L}$ ) as affected by pre-and post-harvest condition: A review. Food Chem 211: 41-50.

Pandey A, Tripathi S. 2014. Concept of standardization, extraction and pre-phytochemical screening strategies for herbal drug. J Pharmacog Phytochem 115 (25): 115-119.

Plaza M, Turner C. 2015. Trends in analytical chemistry pressurized hot water extraction of bioactive. Trends Anal Chem 71: 39-54.

Ramluckan K, Moodley KG, Bux F. 2014. An evaluation of the efficacy of using selected solvents for the extraction of lipids from algal biomass by the soxhlet extraction method. Fuel 116: 103-108.

Rauf A, Nawaz H, Shad MA. 2018. Effect of solvent polarity and extraction time on in vitro antioxidant properties of Brassica oleracea Convar Capitata Var L. seeds. Pak J Pharm Sci 31 (5), 1889-1897.

Seyedan A, Alshawsh MA, Alshagga MA, Koosha S, Mohamed Z. 2015. Medicinal Plants and Their Inhibitory Activities against Pancreatic 
Lipase: A Review. Evid-Based Compl Altern Med 2015: 973143. DOI: $10.1155 / 2015 / 973143$

She LC, Liu CM, Chen CT, Li HT, Li WJ, Chen CY. 2017. The anticancer and anti-metastasis effects of phytochemical constituents from Leucaena leucocephala. Biomed Res 28 (7): 2893-2897.

Shi J, Yu J, Pohorly J, Young JC, Bryan M, Wu Y. 2003. Optimization of the extraction of polyphenols from grape seed meal by aqueous ethanol solution. Food Agric Environ 1 (2): 42-47.

Shuai L, Luterbacher J. 2016. Organic solvent effects in biomass conversion reactions. ChemSos Chem 9: 133-155

Soetjipto H, Pradana RC, Kristijanto AI. 2019. Fatty acid composition and total lipid content of the seed oil of Leucaena leucocephala (Lam) de Wit Fatty acid composition and total lipid content of the seed oil of Leucaena leucocephala ( Lam ) de Wit. IOP Conf Ser: Mater Sci Eng 509: 012046. DOI:10.1088/1757-899X/509/1/012046

Syamsudin, Sumarny R, Simanjuntak P. 2010. Antidiabetic activity of active fractions of Leucaena leucocephala (Lmk) de Wit seeds in experiment model. Eur J Sci Res 43 (3): 384-391.

Sun C, Wu Z, Wang Z, Zhang H. 2015. Effect of ethanol/water solvents on phenolic profiles and antioxidant properties of Beijing propolis extracts. Evid-Based Compl Altern Med 2015: 595393. DOI: $10.1155 / 2015 / 595393$.

Suvachittanont W, Kurashima Y, Esumib H, Tsudac M. 1996. Formation of thiazolidine-4-carboxylic acid (thioproline), an effective nitritetrapping agent in human body, in Parkia speciosa seeds and other edible leguminous seeds in Thailand. Food Chem 55 (4): 359-363.

Tapiero H, Townsend DM, Tew KD. 2004. Organosulfur compounds from Alliaceae in the prevention of human pathologies. Biomed Pharmacother 58 (3): 183-193.

Tocmo R, Liang D, Wang C, Poh J, Huang D. 2016. Organosulfide profile and hydrogen sulfide-releasing capacity of stinky bean (Parkia speciosa) oil: effects of $\mathrm{pH}$ and extraction methods. Food Chem 190: 1123-1129.

Verma S. 2016. A review study on Leucaena leucocephala: a multipurpose tree. Int J Sci Res Sci Eng Technol 2 (2): 103-105.

Xu D, Li Y, Meng X, Zhou T, Zhou Y, Zheng and Zhang J. 2017. Natural antioxidants in foods and medicinal plants: extraction, assessment and resources. Intl J Mol Sci 18 (96): 20-31. 